\title{
The optimal blood glucose target in critically ill patients: more questions than answers
}

\author{
Jan Gunst ${ }^{*}$ and Gordon S. Doig ${ }^{2,3}$
}

(c) 2016 Springer-Verlag Berlin Heidelberg and ESICM

Evoked by severe physiological stress, critically ill patients usually develop hyperglycemia, with the degree of hyperglycemia being associated with progressively worse outcome. One pediatric and two adult single-center randomized controlled trials (RCTs) in Leuven have shown that lowering elevated blood glucose levels to the normal fasting range $(80-110 \mathrm{mg} / \mathrm{dl}$ for adults) with insulin therapy, as compared with tolerating hyperglycemia up to $215 \mathrm{mg} / \mathrm{dl}$, significantly reduced short-term morbidity and mortality [1-3], with the clinical benefit maintained up to 4 years after randomization $[4,5]$. Soon after these studies, tight blood glucose control (TGC) was adopted in many centers. However, controversy exists about the efficacy and safety of TGC $[6,7]$, especially since the benefit was not confirmed in multicenter RCTs, with the largest multicenter study (NICE-SUGAR) even finding excess mortality [8]. One difference that may explain these seemingly opposite results is the comparison with a lower glucose target in the control group (less than $180 \mathrm{mg} / \mathrm{dl}$ in NICE-SUGAR). Indeed, one could argue that most of the benefit is already achieved in this intermediate target range, and that further lowering glucose levels mainly increases the risks, being a higher incidence of hypoglycemia. As a result, current guidelines recommend to target glucose levels less than $180 \mathrm{mg} / \mathrm{dl}$ in critically ill patients, although there is no adequately powered RCT that compared this intermediate target with loose glucose control. Hence, the optimal blood glucose target in critically ill patients remains unclear.

\footnotetext{
*Correspondence: jan.gunst@kuleuven.be

${ }^{1}$ Clinical Division and Laboratory of Intensive Care Medicine, Department of Cellular and Molecular Medicine, KU Leuven, Herestraat 49, 3000 Leuven, Belgium

Full author information is available at the end of the article
}

Yamada et al. and Yatabe et al. aimed to identify an optimal blood glucose target for adult critically ill patients by performing a network meta-analysis $[9,10]$. This statistical approach allows to assess the relative effectiveness of more than two interventions for a given condition, in contrast to conventional pairwise metaanalysis, in which only two treatment strategies are compared [11]. In addition, by combining both direct and indirect comparisons, the latter by using a common comparator, a network meta-analysis can also estimate the effect of two treatments for which no (or only limited) head-to-head comparisons exist. Both network metaanalyses included RCTs investigating different blood glucose targets in adult critically ill patients and categorized study groups into four treatment groups based on the target blood glucose level: a tight blood glucose control group $(80-110 \mathrm{mg} / \mathrm{dl})$, a moderate $(110-140$ or $110-144 \mathrm{mg} / \mathrm{dl}$ in [9], respectively [10]), a mild (140-180 or $144-180 \mathrm{mg} / \mathrm{dl}$, respectively), and a loose blood glucose control group (>180 mg/dl). Both analyses revealed no significant difference in the risk of mortality for any comparison; however, the stricter the glucose target was, the higher the risk of severe hypoglycemia was. Compared to loose control, risk of hypoglycemia was significantly higher with tight or moderate control, but not with mild control. Ranking analysis-another possibility of network meta-analysis-revealed that the moderate and mild groups had the highest probability of being the best treatment with regard to the risk of mortality, whereas the loose group had the highest probability of being the worst treatment. As expected, ranking analysis favored the loose group with regard to the risk of hypoglycemia. On the basis of these data, the authors suggest that intermediate blood glucose levels may have the best risk-benefit profile. Alternatively, one could conclude that stricter

\section{勿


blood glucose control only increases the risk of severe hypoglycemia, without any outcome benefit.

Although network meta-analyses are gaining popularity and a potential source of evidence, we should be cautious not to overinterpret these findings. Indeed, it is important to understand the limitations and assumptions involved [11]. The network meta-analysis assumes that the only difference between trials is the different blood glucose target. However, there are important other methodological differences between the included RCTs that may also explain the seemingly opposite results. These include, among others, the accuracy of the glucose measurements, the feeding strategy, and the insulin infusion protocol [6]. The use of inaccurate glucose monitoring tools in several trials may have exposed patients to an increased risk of undetected and prolonged hypoglycemia. Regarding the feeding regimen, a meta-analysis suggested a relationship between the feeding regimen (the amount of parenteral calories) and the outcome benefit of TGC [12]. Indeed, increasing carbohydrate intake may iatrogenically increase hyperglycemia and associated risks. However, this meta-analysis has the same limitation of not correcting for other methodological differences. Finally, the success of reaching a specific glucose target was poor in several studies, in part explained by the use of unvalidated glucose control algorithms [6]. To assess heterogeneity, the authors performed several sensitivity analyses $[9,10]$. These data show similar results after omission of low quality trials and regardless of the type of ICU, the severity of illness, the actually achieved glucose levels, and the incidence of diabetes. However, other factors were not taken into account. The $I^{2}$ value, which was most often between 30 and $50 \%$, actually indicates low to moderate heterogeneity [13]. Moreover, the significant inconsistency for some comparisons (difference between direct and indirect comparison) supports this.

In summary, the current network meta-analyses aimed to identify an optimal blood glucose target in adult critically ill patients, but could not detect one. This may mean that blood glucose control only increases the risk of hypoglycemia, without any outcome benefit, or that other methodological differences (apart from a different blood glucose target) explain the opposite results between RCTs. The benefit from targeting strict blood glucose levels mainly originates from single-center RCTs [1-3], in which TGC was performed with accurate tools and compared to tolerating severe hyperglycemia. However, the feeding strategy used, which comprised intravenous glucose (400-800 kcal/day for adults) followed by early parenteral nutrition, subsequently turned out to be harmful $[14,15]$. In contrast, a large pragmatic multicenter RCT that compared TGC to an intermediate target in patients receiving less parenteral calories in the acute phase found excess mortality [8]. Hence, the optimal blood glucose target remains to be defined, which may differ according to the available logistics and the feeding regimen. Until evidence from new RCTs becomes available, common sense supports to prevent severe hyperglycemia in all critically ill patients.

\section{Author details \\ ${ }^{1}$ Clinical Division and Laboratory of Intensive Care Medicine, Department of Cellular and Molecular Medicine, KU Leuven, Herestraat 49, \\ 3000 Leuven, Belgium. ${ }^{2}$ The Northern Clinical School Intensive Care Research Unit, University of Sydney, Sydney, Australia. ${ }^{3}$ Intensive Care Unit, Royal North Shore Hospital, Pacific Hwy, St Leonards, NSW 2065, Australia.}

\section{Compliance with ethical standards}

Conflicts of interest

The authors declare to have no conflict of interest.

Received: 21 October 2016 Accepted: 24 October 2016

Published online: 8 November 2016

\section{References}

1. Van den Berghe G, Wouters P, Weekers F, Verwaest C, Bruyninckx F, Schetz M, Vlasselaers D, Ferdinande P, Lauwers P, Bouillon R (2001) Intensive insulin therapy in critically ill patients. N Engl J Med 345:1359-1367. doi:10.1056/NEJMoa011300

2. Van den Berghe G, Wilmer A, Hermans G, Meersseman W, Wouters PJ, Milants I, Van Wijngaerden E, Bobbaers H, Bouillon R (2006) Intensive insulin therapy in the medical ICU. N Engl J Med 354:449-461. doi:10.1056/ NEJMoa052521

3. Vlasselaers D, Milants I, Desmet L, Wouters PJ, Vanhorebeek I, van den Heuvel I, Mesotten D, Casaer MP, Meyfroidt G, Ingels C, Muller J, Van Cromphaut S, Schetz M, Van den Berghe G (2009) Intensive insulin therapy for patients in paediatric intensive care: a prospective, randomised controlled study. Lancet 373:547-556. doi:10.1016/ S0140-6736(09)60044-1

4. Ingels C, Debaveye Y, Milants I, Buelens E, Peeraer A, Devriendt Y, Vanhoutte T, Van Damme A, Schetz M, Wouters PJ, Van den Berghe G (2006) Strict blood glucose control with insulin during intensive care after cardiac surgery: impact on 4-years survival, dependency on medical care, and quality-of-life. Eur Heart J 27:2716-2724. doi:10.1093/eurheartj/ ehi855

5. Mesotten D, Gielen M, Sterken C, Claessens K, Hermans G, Vlasselaers D, Lemiere J, Lagae L, Gewillig M, Eyskens B, Vanhorebeek I, Wouters PJ, Van den Berghe G (2012) Neurocognitive development of children 4 years after critical illness and treatment with tight glucose control: a randomized controlled trial. JAMA 308:1641-1650. doi:10.1001/ jama.2012.12424

6. Gunst J, Van den Berghe G (2016) Blood glucose control in the ICU: don't throw out the baby with the bathwater! Intensive Care Med 42:14781481. doi:10.1007/s00134-016-4350-3

7. Marik PE (2016) Tight glycemic control in acutely ill patients: low evidence of benefit, high evidence of harm! Intensive Care Med 42:14751477. doi:10.1007/s00134-016-4299-2

8. NICE-SUGAR Study Investigators, Finfer S, Chittock DR, Su SY, Blair D, Foster D, Dhingra V, Bellomo R, Cook D, Dodek P, Henderson WR, Hébert PC, Heritier S, Heyland DK, McArthur C, McDonald E, Mitchell I, Myburgh JA, Norton R, Potter J, Robinson BG, Ronco JJ (2009) Intensive versus conventional glucose control in critically ill patients. N Engl J Med 360:1283-1297. doi:10.1056/NEJMoa0810625

9. Yamada T, Shojima N, Noma H, Yamauchi T, Kadowaki T (2016) Glycemic control, mortality, and hypoglycemia in critically ill patients: a systematic review and network meta-analysis of randomized controlled trials. Intensive Care Med. doi:10.1007/s00134-016-4523-0 
10. Yatabe T, Inoue S, Sakaguchi M, Egi M (2016) The optimal target for acute glycemic control in critically ill patients: a network meta-analysis. Intensive Care Med. doi:10.1007/s00134-016-4558-2

11. Cipriani A, Higgins JP, Geddes JR, Salanti G (2013) Conceptual and technical challenges in network meta-analysis. Ann Intern Med 159:130-137. doi:10.7326/0003-4819-159-2-201307160-00008

12. Marik PE, Preiser JC (2010) Toward understanding tight glycemic control in the ICU: a systematic review and meta analysis. Chest 137:544-551. doi:10.1378/chest.09-1737

13. Higgins JPT, Green S (2011) Cochrane handbook for systematic reviews of interventions version 5.1.0. http://www.handbook.cochrane.org. Accessed 20 Oct 2016
14. Casaer MP, Mesotten D, Hermans G, Wouters PJ, Schetz M, Meyfroidt G, Van Cromphaut S, Ingels C, Meersseman P, Muller J, Vlasselaers D, Debaveye Y, Desmet L, Dubois J, Van Assche A, Vanderheyden S, Wilmer A, Van den Berghe G (2011) Early versus late parenteral nutrition in critically ill adults. N Engl J Med 365:506-517. doi:10.1056/NEJMoa1102662

15. Fivez T, Kerklaan D, Mesotten D, Verbruggen S, Wouters PJ, Vanhorebeek I, Debaveye Y, Vlasselaers D, Desmet L, Casaer MP, Guerra GG, Hanot J, Joffe A, Tibboel D, Joosten K, Van den Berghe G (2016) Early versus late parenteral nutrition in critically ill children. N Engl J Med 374:1111-1122. doi:10.1056/NEJMoa1514762 